\title{
Cognitive Radio Techniques over Conventional Radio Systems
}

\author{
Anughna N, Tanuja G, Sunita panda
}

\begin{abstract}
Cognitive Radio (CR) has advanced like a brilliant innovation for crossing over the divergence between the accessibility and assignment of the radio recurrence range among various clients. It can change its transmission parameters dependent on the apparent accessibility of the range groups in its working condition. Cognitive radio (CR) innovation vows to be one potential answer for take care of the issue of absence of recurrence range, by permitting access of unlicensed clients in authorized groups, in view of a shrewd methodology and without meddling with the authorized user(PU). Subjective Radio has developed as a savvy innovation in crossing over the divergence between the accessibility and distribution of the radio recurrence range among numerous clients. This paper shows an outline of the spectrum holes in the licensed bands, the concepts of $C R$, types, spectrum holes, its features and sensing methods the transceiver details and it compares with conventional radio in terms of performance parameters such as interference, operating frequency, security, spectrum utilization, reliability, efficiency and power consumption
\end{abstract}

Keywords : Software Defined Radio (SDR), Cognitive Radio (CR), Dynamic Spectrum Access(DSA).

\section{INTRODUCTION}

Federal Communications Commission distributes fixed frequency spectrum for military, television, cellular etc. applications. However It has been reported that, only $6 \%$ of the fixed distributed RF spectrum is completely used and remaining frequency band is kept idle and goes futile [1].Because of high information rate and Quality of Service (QoS) necessities mass clients for some, applications have brought about request of the rare radio range. This issue can be moderated by the idea of Dynamic Spectrum Access (DSA) [2] that empowers unlicensed clients to astutely get to the un-utilized range of the genuine clients without hurting the current clients. 5G remote systems [3] which have heterogeneous designs with Cognitive Radio (CR) [4] innovation has developed as new worldview to progressively misuse the current underutilized range

Remainder of the paper is surrounded as pursues: First, area II portrays about a concise presentation about customary radio . Second, segment III surveys about subjective radio and its sorts, Third, area IV manages essential activity of range gaps and kinds of range detecting.

Revised Manuscript Received on December 30, 2019.

* Correspondence Author

Anughna N, Assistant Professor, Electronics and communication Engineering department, GITAM University, Bangalore campus.

Tanuja.G, Assistant Professor, Electronics and communication Engineering department, GITAM University, Bangalore campus.

Dr. Sunita Panda, Assistant Professor, Electronics and communication Engineering department, GITAM University, Bangalore campus.

(C) The Authors. Published by Blue Eyes Intelligence Engineering and Sciences Publication (BEIESP). This is an open access article under the CC BY-NC-ND license (http://creativecommons.org/licenses/by-nc-nd/4.0/)
Fourth, Section V centers around CR range detecting and detecting strategies. Fifth, area VI gives highlights of psychological radio, rundown of abbreviations in table I and contrasts between customary radio and intellectual radio in table II .Finally, Section VII highlights about results and section VIII concludes the investigation and portrays the future work.

\section{CONVENTIONAL RADIO}

In customary RF frameworks, every client swarm is dispensed with discrete radio channel (or frequency) that isn't reliant on other client swarm channels (or frequencies). The clients inside the group serves on premise of previously start things out serve to transmit and get on a similar channel.. Transmissions may happen with or without the help of a repeater .Simplex interchanges (transmit and get on the equivalent recurrence) does not use repeater and correspondence takes place one way just over a little region[5]. Regular radio frameworks imparts clients inside a given geographic level of inclusion. A feature of an ordinary radio framework is that numerous clients embraced with distinctively fabricated radios can interface with each other which they are customized to a similar recurrence, that has reasonable programming on CTCSS or DCS. (CTCSS and DCS are strategies regularly used to dismiss the obstruction from other radio frameworks).

\section{COGNITIVE RADIO}

The principle highlight of CR innovation is to perceive empty range divides and at the same time update the working parameters to utilize the range proficiently [6] . The dependable lawful clients who holds range permit are known as Primary Users[7] (PUs) though the Secondary Users (SUs) are low organized clients who can get to essential clients assets. Fig.1. shows the Block diagram of CR transceiver Physical architecture

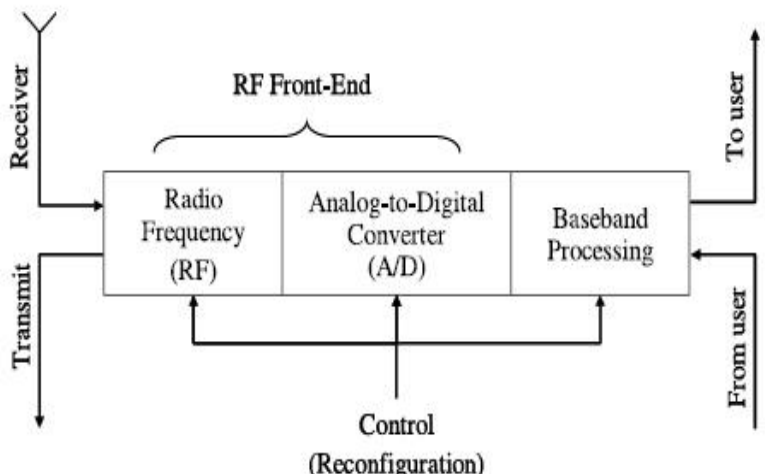

Fig.1. Block diagram of CR transceiver Physical architecture 


\section{Cognitive Radio Techniques over Conventional Radio Systems}

Intellectual Radio has explicit wideband detecting property by means of the RF front end that utilizes recurrence. The wideband RF front end gets authorized sign of shifting data transmission, control levels from different areas [8]. Subsequently, after stringent detecting instrument and adjustment as per got signals, SU correspondence is empowered.

\section{A. Software Defined Radio}

Software Defined Radio(SDR) is a radio correspondence framework which was created by Joseph Mitola in mid 90's.Initial operational SDR called as 'speakeasy' progressed by the United states Navy between 1991and 95.Priorly in gadgets, remote correspondence circuits, reusable and particular programming procedures was utilized in which equipment usage (amplifiers, mixers, modulators and demodulators, detectors and so forth.,) are supplanted by methods for programming execution on a PC or inserted framework. SDR's commonly looks like black box at the end of the day the radio view is a little bit of equipment with less number of a reception apparatus ports and information ports and that incorporates LED [9]. SDR application have a range show which gives a constant perspective on broad swath of the radio dial. With the range show examine the approaching and active sign without really being fixed on them range shows are really a visual portrayal of what is showing on the radio

\section{B. Spectrum sensing cognitive radio}

This type of radio distinguishes directs in the radio recurrence range. Range detecting is progressively turning out to be significant as a result of its tremendous number of utilizations. It uses the range productively and distinguishes adequately different transmissions that recognizes what they are and illuminate focal preparing unit with in the spectrum sensing cognitive radio for the necessary activity.

\section{A. SPECTRUM HOLES}

These are the short lived conceivable outcomes in the approved range. It can be feasibly used by the Cognitive Radio customers. There can be "white space" for example worldly range gaps wherein authorized client isn't utilizing the range saved to it right then and there, along these lines, SUs can get the chance to get to the range of PUs or the "dim space" for example spatial range openings though PUs work just in saved band while the SUs can transmit all the while outside the inclusion region of PUs without upsetting PUs administrations [10] Fig.2. picturizes the transient and spatial range openings.

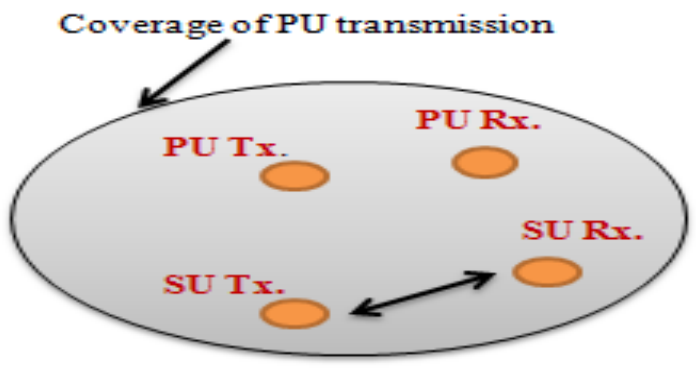

Fig.2. (a) View of Temporal Spectrum Holes

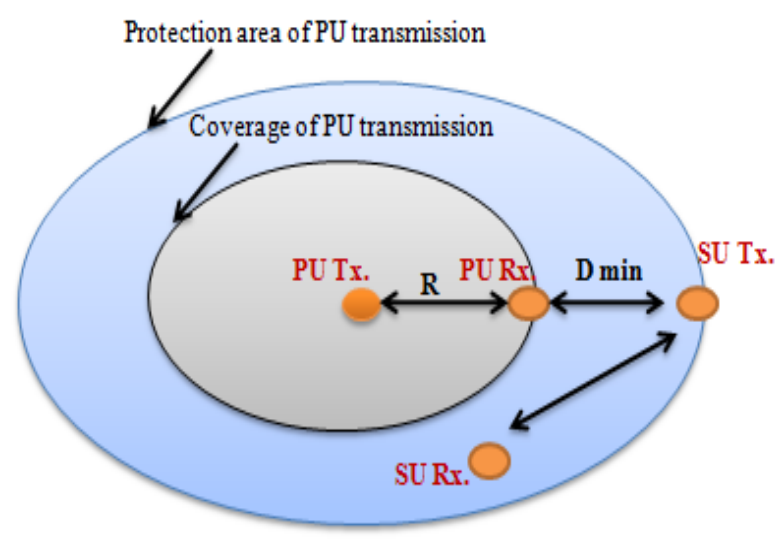

Fig.2. (b) View of Spatial Spectrum Holes

For computerized TV in Japan despite the fact that in the UHF band, 13-52ch are allotted however just 13-15ch and 17-20ch are utilized at certain area while remaining channels stay unused. Accordingly, TV void areas could be utilized for Wireless Local Area Network (WLAN) administration.

Types of spectrum sensing.

1. Non-cooperative spectrum sensing: - This sort of range detecting follows up on its own. It can identify and arrange the information which is now stacked with it.

2. Cooperative spectrum sensing:-This sort of range detecting is taken care of by the quantity of various radios in a subjective radio system. The focal station will change the general subjective radio system according to the got reports from the various radios[11].

\section{BASICS OF CR SPECTRUM SENSING}

1. Continous spectrum sensing--Typically CR system senses continuously the spectrum to occupy and utilise it on a non-interference basis to the primary user.

2. Monitor for alternative empty spectrum--The cognitive radio switches to alternative spectrum if the primary user occupies the spectrum which is already being used .

3. Monitor type of transmission--The type of transmission utilized by the primary user should be known to cognitive radio system so that interference and false transmissions should be ignored.

CR spectrum sensing methods:

1. Spectrum sensing Bandwidth- The first issue related to spectrum sensing bandwidth is to check the number of channels on which system senses the channels and identifies whether it is occupied, simultaneously the system checks for the alternative channels that can be used further.

2. Transmission type sensing- The system should identify the type of transmission of a primary user and must also identify transmissions of other units in the same system. It should also check for the fake signal transmissions[12].

3. Spectrum sensing accuracy- The sensing mechanism should perform in such a way that it detects signal level accurately in the presence of false alarms. 


\section{COGNITIVE RADIO AND ITS FEATURES}

Cognition signifies collecting data through detecting and encounters. The Cognitive Radio concept was reached out by Joseph Mitola III at Royal Institute of Stockholm; Sweden in 1999. CR is a flexible, intelligent radio remote correspondence innovation in which a handset identifies consequently the correspondence channels which are sit or occupied for example "spectrum holes" changes dependent on the present transmitting parameters in its condition immediately gets to the unfilled channels while keeping away from the bustling ones to withstand numerous clients[13]. Fig.3. shows the CR clients acquiring the range by DSA technique.

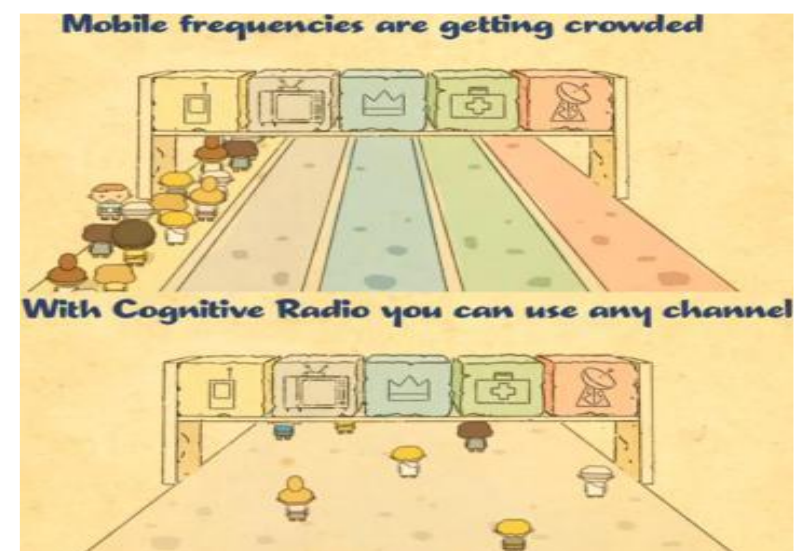

Fig.3. shows the CR clients acquiring the range by DSA technique

Properties of Cognitive Radio include:

1) Cognitive Capability: Potential of the radio to accumulate data about its condition. It includes the cycle of Spectrum Sensing, Spectrum Analysis and Spectrum Decision[14].

2) Re-configurability: Capability to program the $\mathrm{CR}$ empowering a unique recurrence determination, transmission control, data transfer capacity, tweak modification according to range conditions to improve the Quality of Service (QoS)[15].

Table -I : List of Acronyms

\begin{tabular}{|c|c|}
\hline Acronym & Full form \\
\hline FCC & Federal Communication Commission \\
\hline 3 GPP & Third Generation Partnership Project \\
\hline SG & Fifth Generation \\
\hline PU & Secondary User \\
\hline SU & Cognitive Radio \\
\hline CR & Software Defined Radio \\
\hline DSA & Wireless Local Area Network \\
\hline SDR & Continuous Tone-Coded Squelch System \\
\hline WLAN & Digital Coded Squelch \\
\hline CTCSS & Quality of Service \\
\hline DCS & \\
\hline QoS &
\end{tabular}

Table--II: Differences between conventional and cognitive radio

\begin{tabular}{|c|c|c|}
\hline Parameter & Conventional Radio & Cognitive Radio \\
\hline $\begin{array}{c}\text { Radio } \\
\text { channels }\end{array}$ & Limited & Variable \\
\hline Interference & $\begin{array}{c}\text { It is more when signal } \\
\text { strength is low }\end{array}$ & $\begin{array}{l}\text { Based on spectrum } \\
\text { sensing }\end{array}$ \\
\hline $\begin{array}{l}\text { Operating } \\
\text { Frequency }\end{array}$ & $<470 \mathrm{MHz}$ & $470-790 \mathrm{MHz}$ \\
\hline Security & Less secured & $\begin{array}{l}\text { Based on transmission } \\
\text { models }\end{array}$ \\
\hline $\begin{array}{l}\text { Spectrum } \\
\text { Utilization }\end{array}$ & Less & More \\
\hline Complexity & More complex & Less complex \\
\hline $\begin{array}{l}\text { Network } \\
\text { throughput }\end{array}$ & Less Stable & Stable \\
\hline Reliable & Less & More \\
\hline Efficiency & Minimum & Maximum \\
\hline $\begin{array}{c}\text { Power } \\
\text { Consumption }\end{array}$ & Less optimized & More optimized \\
\hline $\begin{array}{l}\text { Infrastructure } \\
\text { costs }\end{array}$ & High & Low \\
\hline $\begin{array}{c}\text { Antenna } \\
\text { Requirements }\end{array}$ & Single band & Multiband \\
\hline $\begin{array}{c}\text { Quality of } \\
\text { Service }\end{array}$ & Better & Good \\
\hline Applications & $\begin{array}{c}\text { Radio } \\
\text { communication, } \\
\text { Radio navigation etc., }\end{array}$ & $\begin{array}{c}\text { Radio communication, } \\
\text { Emergency and public } \\
\text { safety communications, } \\
\text { Geo location, vehicular } \\
\text { communication, } \\
\text { military etc., }\end{array}$ \\
\hline $\begin{array}{c}\text { Countries } \\
\text { which is using } \\
\text { currently }\end{array}$ & All Countries & $\begin{array}{c}\text { North America, } \\
\text { Europe, Asia Pacific, } \\
\text { South America, Middle } \\
\text { east and Africa }\end{array}$ \\
\hline
\end{tabular}

\section{RESULTS}

Comparison between conventional and cognitive radio systems in terms of interference introduced in the primary user vs maximum transmitted data rate is depicted in Fig.4 (a).

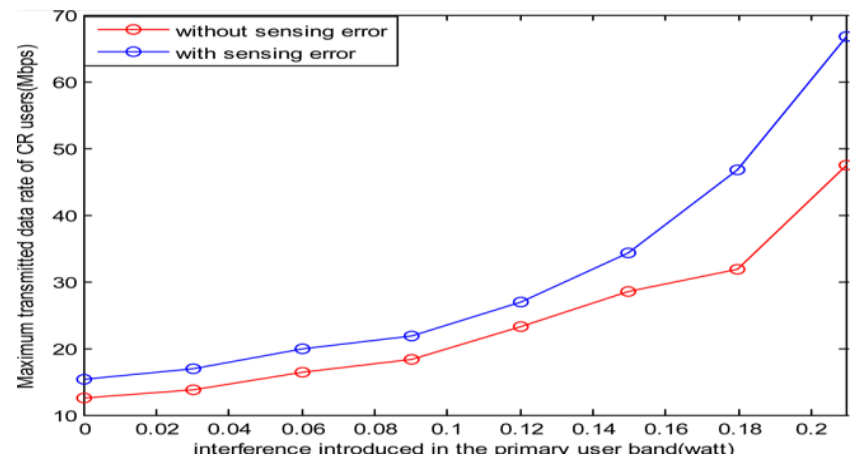

Fig.4(a) Shows results of maximum data rate vs interference in the primary user 


\section{Cognitive Radio Techniques over Conventional Radio Systems}

Arrival rate of the primary user with bandwidth allocation plot related to cognitive radio system is shown in Fig4.(b).

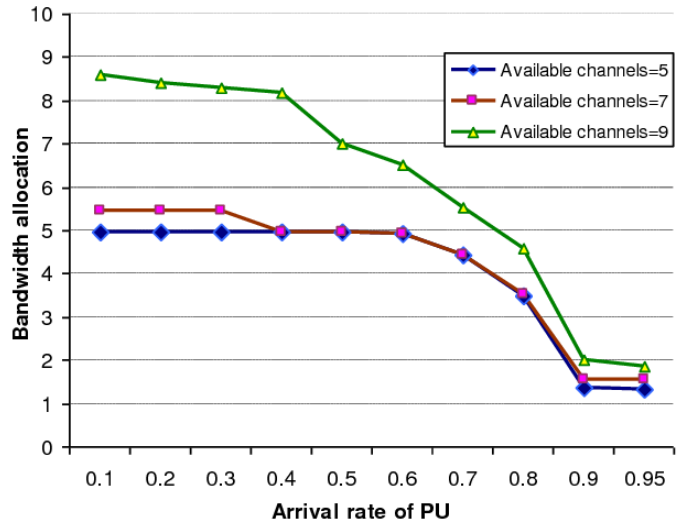

Fig.4(b). Portrays Arrival rate of primary user vs bandwidth allocation

\section{CONCLUSION}

In present era users of wireless communication has lead to a slog in spectrum load. The spectral scarcity problem and resource clogging can be solved using programmable Cognitive Radios that dynamically work in used frequency bands to prolong multiple communications parallel. In this paper a record of what is Cognitive Radio , types and how it adaptively gets to the PU assets is depicted. Different Cognitive Radio range detecting techniques are talked about. A wide examination among ordinary and intellectual radio has been organized later on works, the execution of Cognitive Radio for different pragmatic applications should be possible by using the correlation table.

\section{REFERENCES}

1. Federal Communications Commission, "Spectrum Policy Task Force," Rep. ET Docket no. 02-135, Nov. 2002.

2. Q. Zhao and A. Swami, "A Survey of Dynamic Spectrum Access Signal Processing and Networking Perspectives," IEEE International Conference on Acoustics, Speech and Signal Processing, Vol. 4, pp. 1350-1352, 2007.

3. F.Akyildiz, W.Y. Lee, M. C. Vuran, and S. Mohanty, "NeXt generation/dynamic spectrum access/cognitive radio wireless networks: A survey," Elsevier Computer Networks, Vol. 50, pp. 2127-2159, 2006.

4. J. Mitola, "Cognitive radio for flexible mobile multimedia communication," in Proc. IEEE Int. Workshop Mobile Multimedia Commun. (MoMuC), San Diego, CA, USA, Nov. 1999, pp. 3-10.

5. Abdelrahim Mohamed, Oluwakayode Onireti, Muhammad Ali Imran,Ali Imran, and Rahim Tafazolli, “ Control-Data Separation Architecture for Cellular Radio Access Networks: A Survey and Outlook" IEEE Communications survey and tutorials vol. 18, no. 1, first quarter 2016.pp.446-465.

6. H Venkataraman, GM Muntean “ Cognitive Radio and its application for next generation cellular and wireless networks" 2012-springer.

7. Y Saleem,MH Rehmani "Primary radio user activity models for cognitive radio networks:A survey",Journal of network and computer applications,2014-Elsevier.

8. S. Venkateswari, R. Muthaiah "An Overview of cognitive Radio Architecture a review"-Journal of theoretical and applied information technology $15^{\text {th }}$ july 2012.pp.20-25.

9. J. Mitola, "Cognitive Radios: Making Software Radios More Personal," IEEE Personal Communication, 6(4), 13-18, 1999.

10. I Christian, S Moh, I Chung, J Lee "Spectrum Mobility in Cognitive radio networks"-IEEE Communications , 2012.

11. Fatima Salahdine "Spectrum Sensing Techniques for Cognitive radio Networks" STRS lab,National institute of posts and telecommunications, chapter 1-2 oct5,2017.

12. Parnika De and Shailendra singh "Journey of mobile generations and cognitive radio technology in 5G"-International Journal of Mobile
Network Communications \& Telematics-Vol 6,no4/5/6 December2016.

13. Ridhima, Avtar singh Buttar "Fundamental operations on cognitive radio: A survey"-IEEE International conference on Electrica ,computer and communication technologies(ICECCT)-17 oct 2019.

14. Fang hu, Bing chen, Kun zhu "Full spectrum sharing in cognitrive radio networks towards 5G:A survey" Feb5, 2018.

15. Harit Mehta "Recent advances in cognitive radios"-April30,2014

\section{AUTHORS PROFILE}

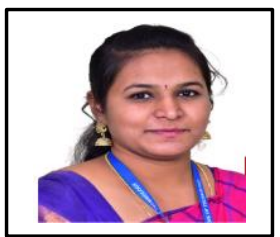

Anughna $\mathbf{N}$, is with Electronics and communication Engineering department, GITAM University, Bangalore campus. Currently she is Assistant Professor, Her areas of interest are Digital communication, Networking, 5G Technologies. She can be reached at anughna.7@gmail.com

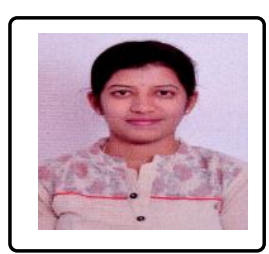

Tanuja.G, is with Electronics and communication Engineering department, GITAM University, Bangalore campus. Currently she is Assistant Professor, Her areas of interest are Digital communication, Networking, 5G Technologies. She can be reached at tanuja.g20@gmail.com

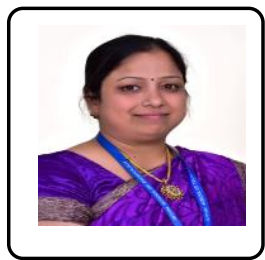

Dr. Sunita Panda, is with Electronics and communication Engineering department, GITAM University, Bangalore campus. Currently she is Assistant Professor, Her areas of interest are soft computing, channel equalization, Digital Signal processing. She can be reached at Sunita.nano@gmail.com 